This article was downloaded by: [Franzini, Maria]

On: 6 November 2009

Access details: Access Details: [subscription number 916564472]

Publisher Informa Healthcare

Informa Ltd Registered in England and Wales Registered Number: 1072954 Registered office: Mortimer House, 37-41 Mortimer Street, London W1T 3JH, UK

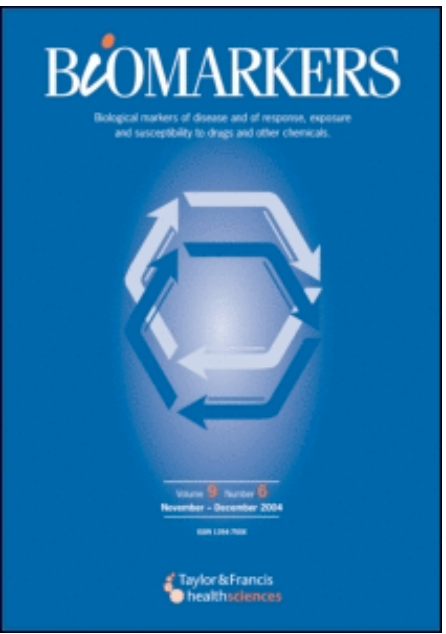

\title{
Biomarkers
}

Publication details, including instructions for authors and subscription information:

http://www.informaworld.com/smpp/title content=t713693137

\section{Cultured human cells release soluble -glutamyltransferase complexes corresponding to the plasma b-GGT}

Maria Franzini a; Alessandro Corti b; Irene Fornaciari a; Michela Balderi b; Francesca Torracca b; Evelina Lorenzini ${ }^{\mathrm{b}}$; Angelo Baggiani ${ }^{\mathrm{b}}$; Alfonso Pompella ${ }^{\mathrm{b}}$; Michele Emdin ${ }^{\mathrm{c}}$; Aldo Paolicchi ${ }^{\mathrm{b}}$

a Scuola Superiore S. Anna, Pisa, Italy ${ }^{b}$ Department of Experimental Pathology, University of Pisa, Italy ${ }^{c}$

Cardiovascular Medicine Department, G. Monasterio Foundation, CNR-Regione Toscana, Pisa, Italy

Online Publication Date: 01 November 2009

To cite this Article Franzini, Maria, Corti, Alessandro, Fornaciari, Irene, Balderi, Michela, Torracca, Francesca, Lorenzini, Evelina, Baggiani, Angelo, Pompella, Alfonso, Emdin, Michele and Paolicchi, Aldo(2009)'Cultured human cells release soluble glutamyltransferase complexes corresponding to the plasma b-GGT',Biomarkers, 14:7,486 - 492

To link to this Article: DOI: $10.3109 / 13547500903093757$

URL: http://dx.doi.org/10.3109/13547500903093757

\section{PLEASE SCROLL DOWN FOR ARTICLE}

Full terms and conditions of use: http://www.informaworld.com/terms-and-conditions-of-access.pdf

This article may be used for research, teaching and private study purposes. Any substantial or systematic reproduction, re-distribution, re-selling, loan or sub-licensing, systematic supply or distribution in any form to anyone is expressly forbidden.

The publisher does not give any warranty express or implied or make any representation that the contents will be complete or accurate or up to date. The accuracy of any instructions, formulae and drug doses should be independently verified with primary sources. The publisher shall not be liable for any loss, actions, claims, proceedings, demand or costs or damages whatsoever or howsoever caused arising directly or indirectly in connection with or arising out of the use of this material. 


\title{
Cultured human cells release soluble $\gamma$-glutamyltransferase complexes corresponding to the plasma b-GGT
}

\author{
Maria Franzini ${ }^{1}$, Alessandro Corti ${ }^{2}$, Irene Fornaciari ${ }^{1}$, Michela Balderi ${ }^{2}$, Francesca Torracca ${ }^{2}$, \\ Evelina Lorenzini ${ }^{2}$, Angelo Baggiani ${ }^{2}$, Alfonso Pompella ${ }^{2}$, Michele Emdin $^{3}$, and Aldo Paolicchi ${ }^{2}$ \\ ${ }^{1}$ Scuola Superiore S. Anna, Pisa, Italy, ${ }^{2}$ Department of Experimental Pathology, University of Pisa, Italy, and \\ ${ }^{3}$ Cardiovascular Medicine Department, G. Monasterio Foundation, CNR-Regione Toscana, Pisa, Italy
}

\begin{abstract}
Serum $\gamma$-glutamyltransferase (GGT) is thought to derive from the liver, but its values predict morbidity and mortality for several diseases, such as cardiac infarction, stroke, diabetes, renal failure and cancer. We assessed total GGT and its fractions in the culture supernatants of human cell lines (melanoma, prostate cancer, bronchial epithelium) by gel filtration chromatography. We also compared the GGT elution profile in plasma and the corresponding very-low-density lipoprotein (VLDL) fraction. All the cell lines tested released soluble GGT whose activity increased in parallel with the cell growth. Released GGT presented a molecular weight of $2000 \mathrm{kDa}$, identical to the b-GGT fraction of human plasma and corresponding to that of VLDL. But ultracentrifugation studies showed that b-GGT had a higher density than VLDL. The b-GGT present in human plasma can be produced by tissues other than the liver, thus explaining the increase of serum GGT observed in diseases of other organs.
\end{abstract}

Keywords: $\gamma$-Glutamyltransferase activity; $\gamma$-glutamyltransferase fractions; gel filtration chromatography; $\gamma$-glutamyltransferase release

\section{Introduction}

$\gamma$-Glutamyltransferase (GGT) is a cell membrane enzyme that catalyses the hydrolysis of extracellular glutathione. Despite virtually all cell types displaying GGT activity and high GGT activity being attained in several tissues such as kidney, bile ducts, choroid plexus and testis, serum GGT is thought to derive exclusively from the liver (Whitfield 2001). While serum GGT is widely used as a biomarker of liver dysfunction and excessive alcohol use (Whitfield 2001), studies of the past decade have revealed that GGT values are positively associated with the risk of cardiovascular events, either in unselected populations (Ruttmann et al. 2005, Meisinger et al. 2006, Wannamethee et al. 1995), or in patients with ascertained cardiovascular disease (Emdin et al. 2001). GGT values have also been found to predict hypertension, type II diabetes and metabolic syndrome (Lee et al. 2003, 2004, 2007), and recent studies have shown a predictive value of GGT for diseases such as renal failure (Ryu et al. 2007) and cancer, even unrelated with hepatic involvement (Kazemi-Shirazi et al. 2007). This raises the suspicion that GGT derived from diseased tissues other than liver might contribute to serum GGT activity, thus explaining its broad predictive value.

GGT activity in blood has long been known to be associated with several complexes of different molecular weights, thought to be lipoproteins (Huseby 1982, Wenham et al. 1984, Nemesanszky \& Lott 1985), but these studies were performed, due to the modest sensitivity of the methods adopted, in patients with above-range values of serum GGT. Only recently a method has been devised that allows the sensitive and reproducible determination of four GGT fractions in the blood of healthy individuals (Franzini et al. 2008): b-GGT ( $>2000 \mathrm{kDa}$ ),

Address for Correspondence: Maria Franzini, Scuola Superiore Sant'Anna, Pisa, Italy; c/o Istituto di Fisiologia Clinica - CNR, Via Moruzzi, 1, I-56124 Pisa, Italy. Tel.: (39)-050-3153309. Fax: (39)-050-3152166. E-mail: franzini@biomed.unipi.it

(Received 10 May 2009; accepted 03 June 2009) 
m-GGT (940 kDa), s-GGT (140kDa), f-GGT (70 kDa). The knowledge of the precise nature, tissue origin and pathophysiological significance of these GGT fractions might allow the identification of extrahepatic tissuespecific forms of this enzyme, which could improve the clinical utilization that has been envisaged based on the existing methods (Huseby 1982, Wenham et al. 1984, Nemesanszky \& Lott 1985, Sacchetti et al. 1988).

In the present study we show that cultured cancer and immortalized human cells of different origin are a source of soluble GGT, and that the enzyme released by these cells displays characteristics corresponding to those of the b-GGT fraction present in the plasma of healthy individuals.

\section{Materials and methods}

\section{Chemicals}

Unless otherwise indicated, all reagents were from Sigma Chemical Co. (St Louis, MO, IL, USA).

\section{Cell lines and culture conditions}

Three different human cell clones expressing different GGT activities were obtained by stable transfection of low-expressing GGT activity clones $\left(<1 \mathrm{mU} \mathrm{mg}^{-1}\right.$ cellular proteins) with a vector containing the fulllength cDNA of human GGT, as previously described (Franzini et al. 2006, Corti et al. 2008): the c21/GGT clone $\left(90.78 \pm 3.40 \mathrm{mU} \mathrm{mg}^{-1}\right.$ protein) was obtained from Me665/2/21 human melanoma clone (c21); the DU145/ GGT clone (185.5 $\pm 6.6 \mathrm{mU} \mathrm{mg}^{-1}$ protein) was obtained from DU145 human prostatic carcinoma clone; BEAS/ GGT ('E1 clone'; $4.1 \pm 0.2 \mathrm{U} \mathrm{mg}^{-1}$ cellular proteins) was obtained from BEAS-2B human bronchial epithelial cells.

Both the c21/GGT and DU145/GGT cell lines, and the correspondinglinestransfected with theemptyvectorwere routinely grown in RPMI 1640 medium, supplemented with $5 \%(\mathrm{v} / \mathrm{v})$ heat-inactivated fetal calf serum, $2 \mathrm{mM}$ L-glutamine (L-Gln) and $0.2 \mathrm{mg} \mathrm{ml}^{-1}$ G418 (Invitrogen/ Gibco, Milan, Italy), at $37^{\circ} \mathrm{C}$ in a $5 \% / 95 \% \mathrm{CO}_{2} /$ air atmosphere. BEAS/GGT and BEAS/basal cells were routinely grown in $\mathrm{BEGM}^{\circledR}$ medium (Cambrex, Walkersville, $\mathrm{MD}$, USA), supplemented with $2 \mathrm{mM} \mathrm{L-Gln}$ and $0.2 \mu \mathrm{g} \mathrm{ml}^{-1}$ $\mathrm{G} 418$, at $37^{\circ} \mathrm{C}$ in a $5 \% / 95 \% \mathrm{CO} 2 /$ air atmosphere.

\section{Preparation of very-low-density lipoproteins by ultracentrifugation}

Blood was obtained from six subjects after an overnight fasting, collected into tubes containing EDTA and centrifuged $(1500 \mathrm{~g}, 10 \mathrm{~min})$. Plasma was mixed to obtain two samples $(4.5 \mathrm{ml})$ having total GGT activity of 19 and $60 \mathrm{U} \mathrm{l}^{-1}$, respectively. VLDL were separated from plasma by ultracentrifugation $\left(100000 \mathrm{~g}, 24 \mathrm{~h}, 15^{\circ} \mathrm{C}\right)$ in a Beckman ultracentrifuge with a fixed angle type 40 rotor. Top fractions containing VLDL were collected to analyse cholesterol and GGT activity elution profile by high-performance gel filtration chromatography.

\section{Determination of total GGT activity}

Incubation media were centrifuged at $10000 \mathrm{~g}(10 \mathrm{~min}$, $4^{\circ} \mathrm{C}$ ) before GGT activity determination in order to remove floating whole cells or rough cell debris. Cell monolayers were harvested with hypotonic lysis buffer (10 mM Tris-HCl, $\mathrm{pH} 7.8$ ).

Determination of GGT activity was performed according to Huseby and Strømme (1974) using $\gamma$-glutamyl$p$-nitroanilide as a substrate and glycyl-glycine as a transpeptidation acceptor.

\section{Fractional GGT analysis by high-performance gel filtration chromatography}

Determination of GGT fractions was performed as previously described (Franzini et al. 2008), by a HPLC System Gold apparatus (Beckman 126) equipped with a $100 \mu \mathrm{lloop}$ and a spectrofluorometric detector (821-FP; Jasco, Tokyo, Japan). Separation was performed by gel filtration chromatography using a Superose 6 HR 10/300 GL column (GE Healthcare, Amersham, UK) by isocratic elution with $0.1 \mathrm{~mol} \mathrm{l}^{-1}$ sodium phosphate buffer (pH 7.4) containing $0.2 \mathrm{~mol} \mathrm{l}^{-1} \mathrm{NaCl}, 0.1 \mathrm{mmol} \mathrm{l}^{-1}$ EDTA and $5.4 \mathrm{mmol} \mathrm{l}^{-1}$ GlyGly to support GGT reaction. Flow rate was set at $0.5 \mathrm{ml} \mathrm{min}^{-1}$. The column was calibrated for molecular weight determination using a mixture of standard proteins of known molecular weight. Media samples were filtered with a $0.45-\mu \mathrm{m}$ PVDF filter (Millipore) before injection. Total run time was $50 \mathrm{~min}$.

The flow eluting from the HPLC column was mixed post-column in a low-dead-volume mixing tee with the $\gamma$-glutamyl-7-amido-4-methylcoumarin (gGluAMC) fluorescent substrate delivered by a syringe pump (Braun) operating at a flow rate of $0.1 \mathrm{ml} \mathrm{min}^{-1}$. Enzymatic reaction proceeded for $4.5 \mathrm{~min}$ in a reaction coil (PFA, 2.6ml) kept at the constant temperature of $37^{\circ} \mathrm{C}$ in a water bath. The AMC signal was specifically detected by a fluorescence detector operating at excitation wavelength $\lambda_{\mathrm{ex}}=380 \mathrm{~nm}$ and emission wavelength $\lambda_{\mathrm{em}}=440 \mathrm{~nm}$. Intensity of the fluorescence signal was expressed in arbitrary fluorescence units (f.u.).

\section{Cholesterol analysis by high-performance gel filtration chromatography}

Distribution profile of cholesterol in VLDL fractions was obtained by applying fractional GGT analysis method, but a commercially available reagent for total cholesterol 
determination (Giesse Diagnostic, Rome, Italy) was used as post-injected reagent. Reaction product was detected by recording the absorbance at $510 \mathrm{~nm}$.

\section{Western blot analysis}

Aliquots of cell homogenates ( $10 \mu \mathrm{g}$ of proteins) were separated by $10 \%$ SDS-PAGE, and gels were blotted onto nitrocellulose membranes. Blots were incubated overnight with a rabbit anti-GGT antiserum (1:10 000 in PBS, containing $0.01 \%$ Tween-20) directed against the C-terminal 20 amino acids of human GGT heavy chain. Visualization of protein bands was obtained using a peroxidase-conjugated antirabbit IgG antibody and an enhanced chemiluminescence detection kit (Roche, Basle, Switzerland).

\section{Other determinations}

Protein content was assayed by the method of Bradford (Bio-Rad protein assay). Statistical analysis of data was performed by one-way ANOVA, followed by post test for linear trend.

\section{Results}

\section{Comparison of the physical properties of VLDL and $b$-GGT}

In both human plasma pools the expected four GGT fractions (b-, m-, s-, f-GGT) were found. VLDL obtained by plasma ultracentrifugation showed the same
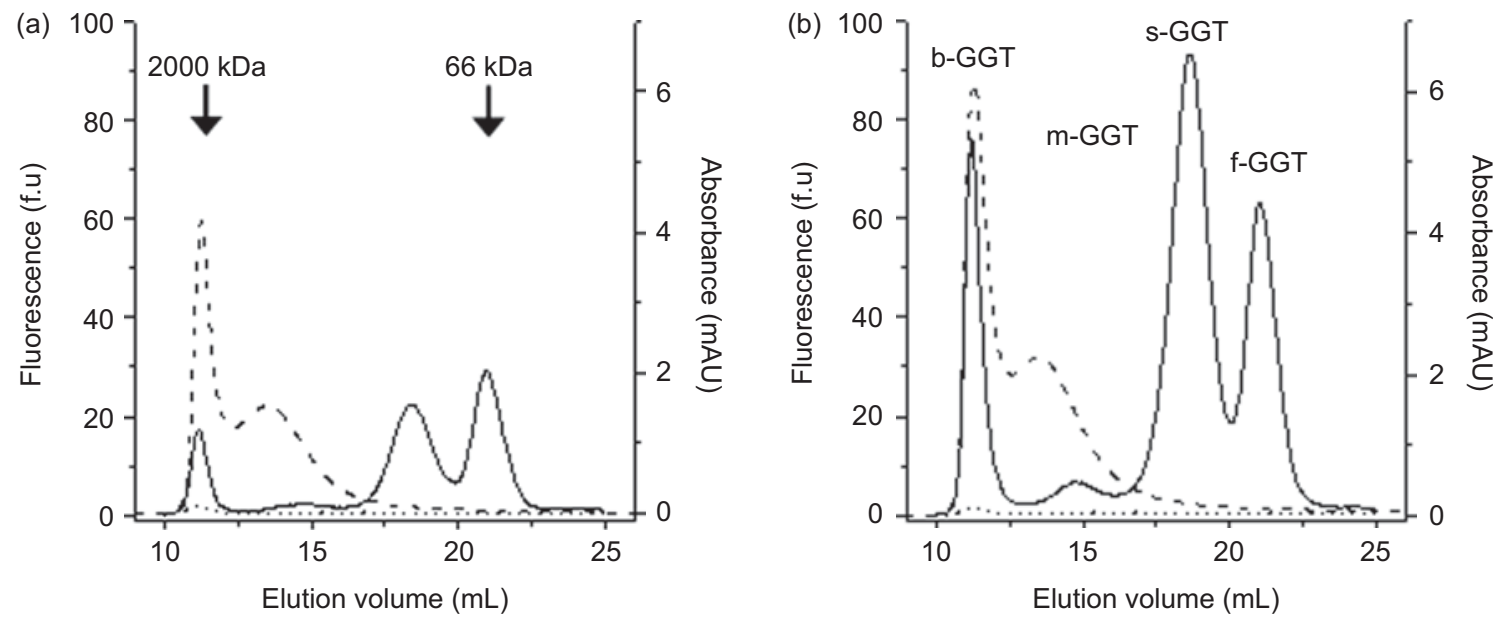

Figure 1. Online $\gamma$-glutamyltransferase (GGT)-specific elution profile of two plasma samples (continuous line) with total GGT activity of $19 \mathrm{U} \mathrm{l}^{-1}$ (a) and $60 \mathrm{U} \mathrm{l}^{-1}$ (b). Corresponding elution profiles of cholesterol (dashed line) and GGT activity associated with very-low-density lipoprotein fraction (dotted line) are shown.
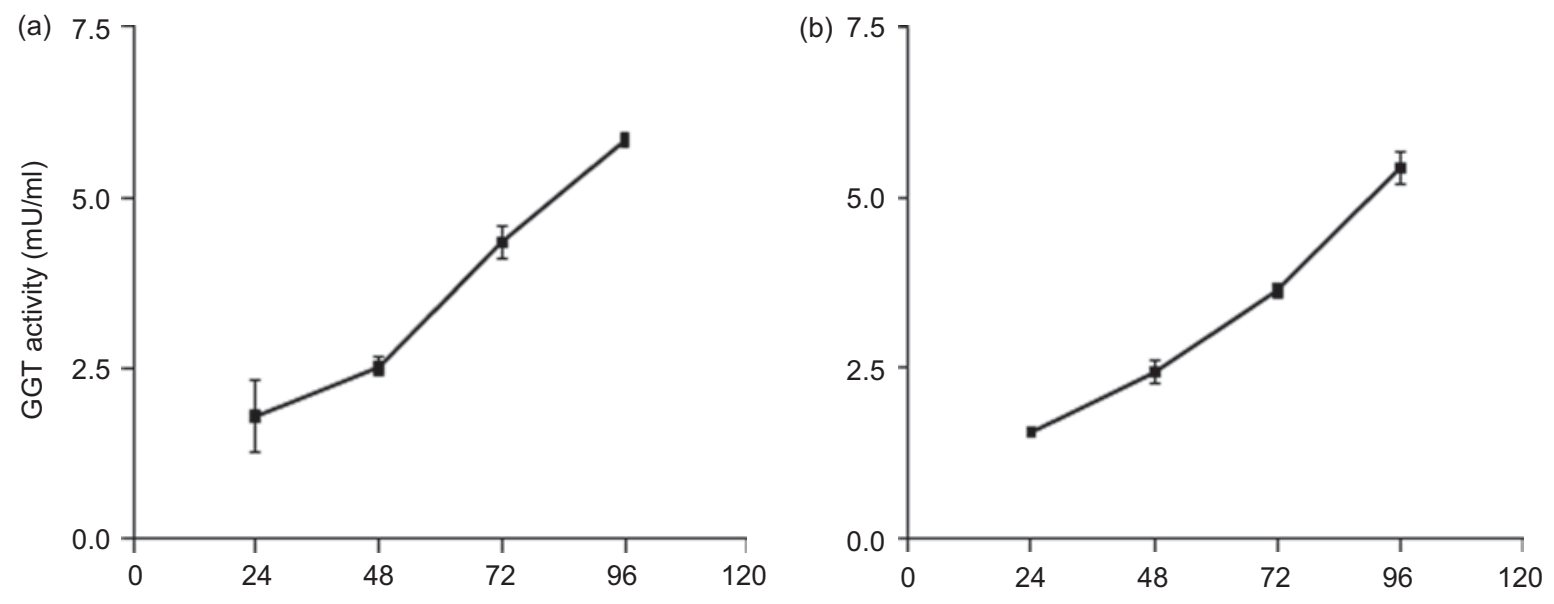

Figure 2. $\gamma$-Glutamyltransferase (GGT) release in culture media of melanoma c21/GGT cells (a) and prostate cancer DU145/GGT cells (b). Cells were seeded at a density of $2 \times 10^{4}$ cells cm cm $^{-2}$ (c1/GGT) and $1.5 \times 10^{4} \mathrm{cells} \mathrm{cm}^{-2}$ (DU145/GGT), respectively. At the established times aliquots of culture media were collected and analysed for GGT activity. Results are means \pm SD of three separate experiments. Data were analysed by oneway ANOVA with post test for linear trend; $p<0.0001$ for both clones. 
molecular weight (MW) as b-GGT, but no GGT activity (Figure 1A, B), all of the plasma b-GGT activity being recovered in the VLDL-depleted plasma (not shown).

\section{GGT release from different cell lines}

A time-dependent increase of GGT activity was observed in the supernatants of c21/GGT and DU145/GGT clones during culture (Figure 2A, B). The increase of enzyme activity in the supernatant was found to parallel the increase of the protein content of the cultures, both in c21/GGT and in the DU145/GGT clone. The DU145/GGT clone, displaying a higher GGT activity, released a proportionally higher GGT activity in the medium (Figure 3A, B).

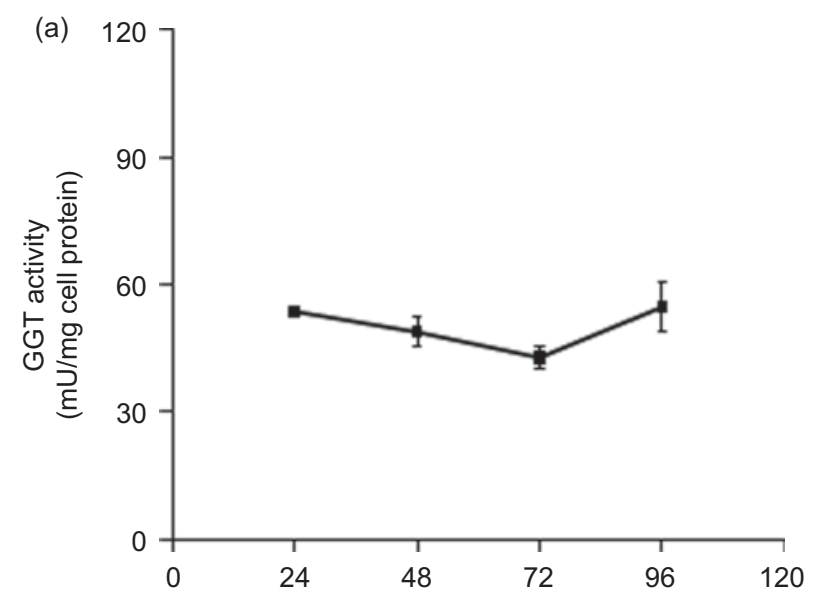

The specific GGT activity of cell homogenates did not change in the c21/GGT clone during the 96h incubation, while a statistically significantincrease was found in DU/145 cells (Figure 4a, b). Stability tests of the GGT released in the culture medium did not reveal enzyme activity loss during the $96 \mathrm{~h}$ duration of the experiment (not shown).

\section{GGT analysis of cell culture supernatants by gel filtra- tion chromatography}

Gel filtration chromatography of the culture media of c21/GGT and DU145/GGT clones revealed in both the presence of one major peak of activity eluting at $11.2 \mathrm{ml}$ (corresponding to a $\mathrm{MW}>2000 \mathrm{kDa}$ ), and of a second

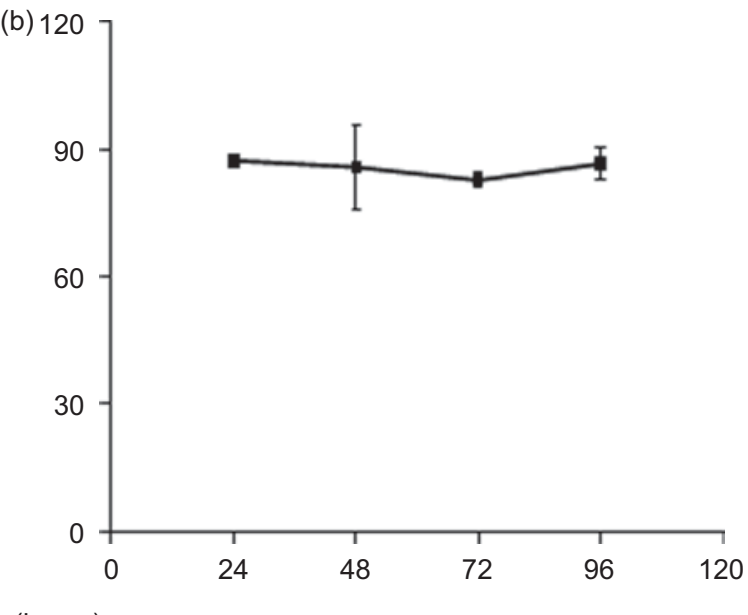

Figure 3. Specific $\gamma$-glutamyltransferase (GGT) activity in culture media of melanoma c21/GGT cells (a) and prostate cancer DU145/GGT cells (b). Cells were seeded at a density of $2 \times 10^{4}$ cells cm$~^{-2}$ (c21/GGT) and $1.5 \times 10^{4}$ cells cm$^{-2}$ (DU145/GGT), respectively. Results are means \pm SD of three separate experiments and were obtained by normalizing GGT activity in cell culture media on total cellular protein content. Data were analysed by two-way ANOVA; $p<0.0001$ for c21/GGT vs DU145/GGT.

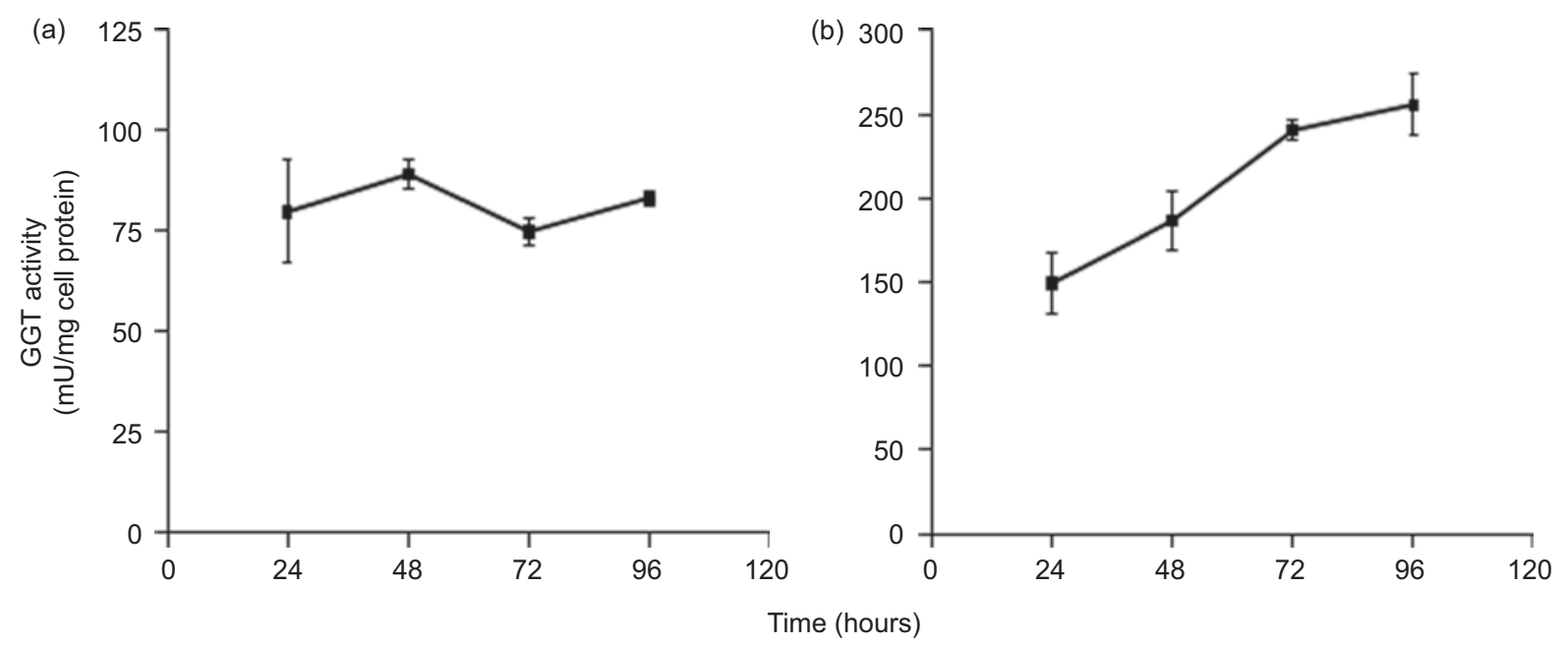

Figure 4. Cellular $\gamma$-glutamyltransferase (GGT) activity of c21/GGT melanoma cells (a) and DU145/GGT prostatic cancer cells (b). Cells were seeded at a density of $2 \times 10^{4}$ cells cm-2 (c21/GGT) and $1.5 \times 10^{4} \mathrm{cells} \mathrm{cm}^{-2}$ (DU145/GGT), respectively. At the established times cells were harvested, homogenized and analysed for their GGT activity. Results are means \pm SD of three separate experiments. Data were analysed by one-way ANOVA with Newman-Keuls test for multiple comparisons. Data were analysed by one-way ANOVA, post-test for linear trend gave the following results: not significant for 21/GGT cells, $p<0.0001$ for DU145/GGT cells. 
(a)
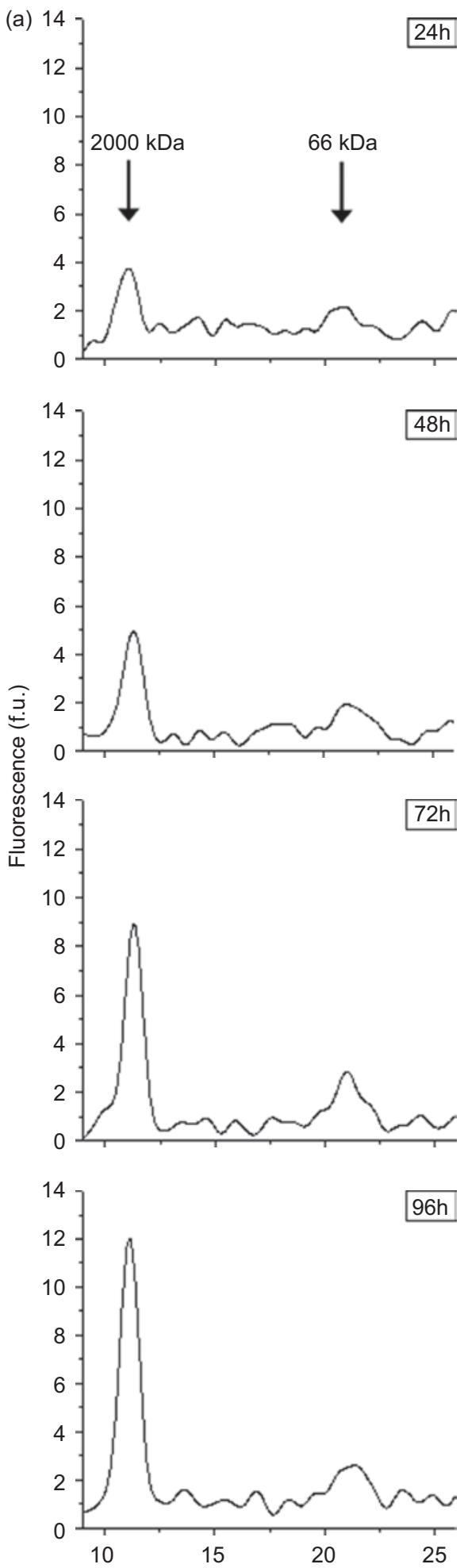

(b)
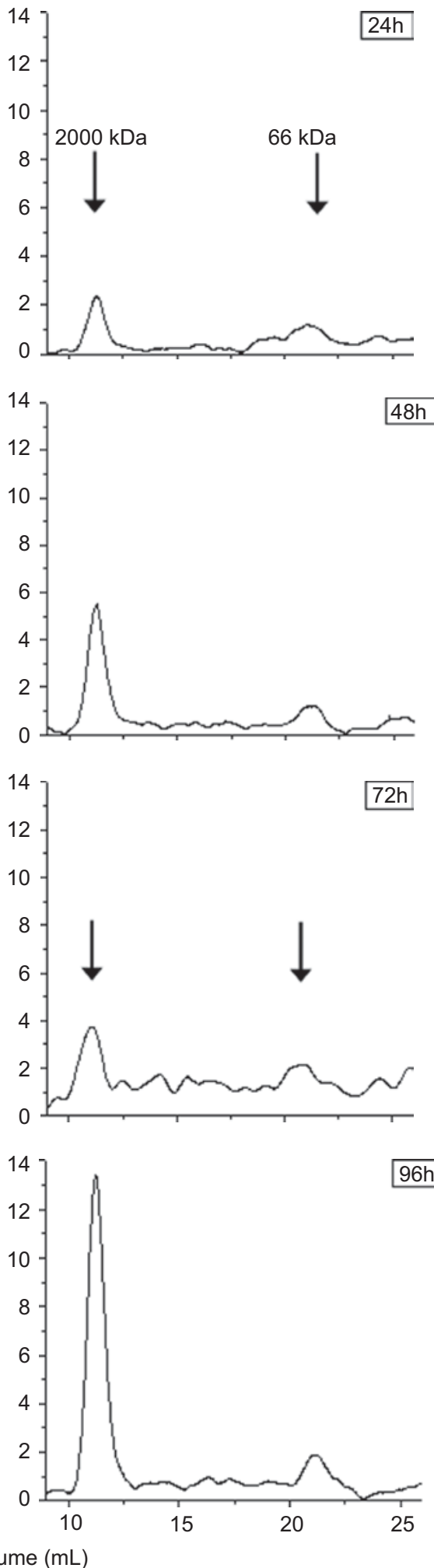

Figure 5. Online $\gamma$-glutamyltransferase (GGT)-specific elution profile of representative medium samples from cultured DU145/GGT prostatic cancer cells (a) and c21/GGT melanoma cells (b). 
peak, less represented, eluting at $21.1 \mathrm{ml}$ (corresponding to a MW of $66 \mathrm{kDa}$ ). The progressive increase of GGT in the medium with culture time was due to a selective increase of the first peak (Figure 5A, B).

To exclude the possibility that the high MW of the GGT released by c21/GGT and in DU145/GGT clones was due to the association of the released GGT with components present in the bovine serum contained in the culture medium, the human immortalized bronchial epithelial cell line BEAS/GGT, routinely grown in serum-free culture medium, was also tested for the release of GGT in the medium. Analysis of the BEAS/GGT supernatant showed the same two GGT peaks previously observed in cancer cell medium, with a prevalence and progressive increase of the one peak with a higher MW, corresponding to b-GGT (Figure 6).

\section{Western blot analysis of cell culture supernatants}

Western blot analysis of the cell homogenates, conducted with an antibody directed against the heavy chain of GGT, showed in all the cell lines, the presence of the expected peptide in all the cell lines adopted in the present study. Only in BEAS/GGT homogenates there was a second band with a higher MW present, corresponding to the MW of the uncleaved GGT propeptide (Figure 7).

\section{Discussion}

The main finding of this study is that cultured melanoma, prostate cancer and bronchial epithelial cells release soluble GGT that corresponds to a specific GGT fraction (b-GGT) found in human plasma (Franzini et al. 2008); tissues other than liver might thus contribute to the levels of circulating GGT by increasing the plasma levels of a specific form of the enzyme. These findings might help explain why GGT is increased in several unrelated diseases not involving the liver, including cancer (Kazemi-Shirazi et al. 2007), and might add to the complex understanding of this sensitive biomarker (Whitfield 2001).

The enzyme fraction released in vitro is stable in the culture medium, is not degraded to other GGT fractions with lower MW, and the amount released is proportional to the specific GGT activity and to the number of cells present in the cultures, thus acting as a potential biomarker of the presence, amount and specific activity of GGT-positive cells.

Ultracentrifugation studies also showed that the corresponding fraction found in plasma, the b-GGT, despite showing the same MW as VLDL, displays a higher density, thus showing that b-GGT found in plasma is not simply due to the absorption of GGT over VLDL, but

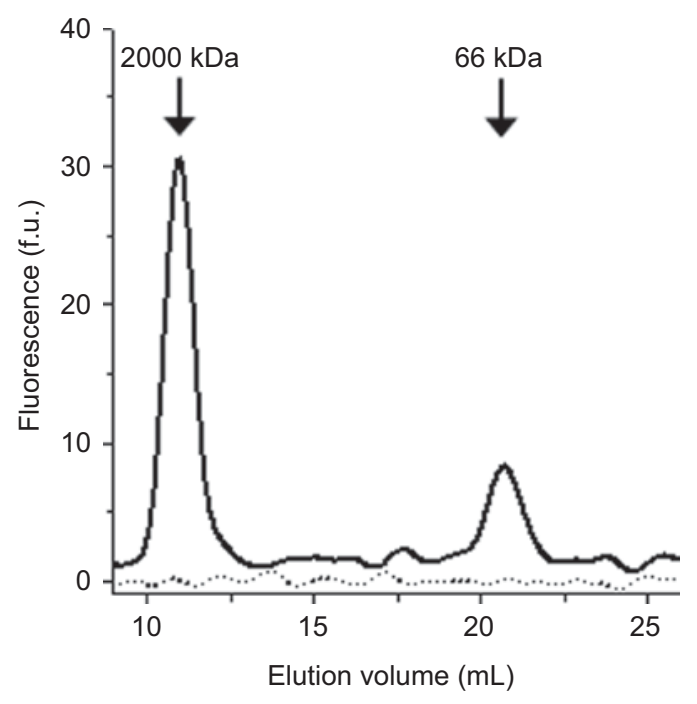

Figure 6. Online $\gamma$-glutamyltransferase (GGT)-specific elution profile of a representative medium sample from cultured BEAS/GGT (continuous line) and BEAS-2B cells, the basal clone (dotted line) after $72 \mathrm{~h}$ in culture.

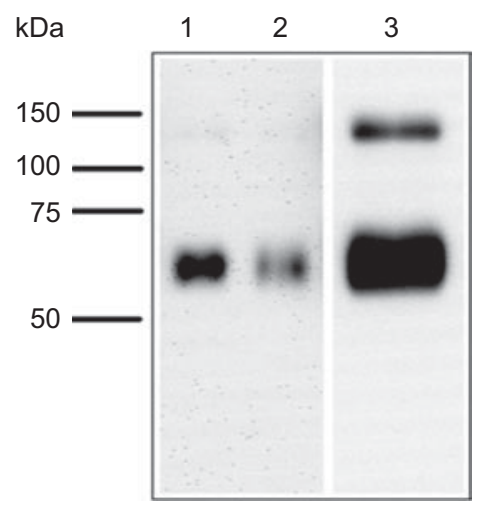

Figure 7. Western blot analysis of the cell homogenates, conducted with an antibody directed against the heavy chain of $\gamma$-glutamyltransferase (GGT). Proteins were separated by $10 \%$ SDSPAGE and gels were blotted onto nitrocellulose membranes. AntiGGT antiserum was directed against the C-terminal 20 amino acids of human GGT heavy chain. Lane 1, c21/GGT; lane 2, DU145/GGT; lane 3, BEAS/GGT.

corresponds to a specific particle whose properties are similar to the b-GGT obtained in vitro.

Only liver GGT is thought to circulate in blood, as peptidase-purified GGT obtained from other tissues is quickly removed in vivo due to its low content of sialic acid and consequently to its reduced surface charge (Mortensen \& Huseby 1997). Anyway, as the GGT found in all the transfected cell lines showed the expected large subunit peptide (Visvikis et al. 1991), the $2000 \mathrm{kDa}$ b-GGT necessarily includes component molecules still to be identified to meet the observed MW. These molecules are likely to determine the biological properties of the particles - including its half-life in blood - much more than GGT itself, thus 
opening the possibility of a longer half-life of extrahepatic b-GGT in vivo.

b-GGT is the only fraction of serum GGT found in atherosclerotic plaques (Franzini et al. 2009) co-localized with oxidized LDL lipoproteins and $\mathrm{CD}^{+}{ }^{+}$foam cells (Paolicchi et al. 2004), potentially involved in the progression of the atherosclerotic plaque (Emdin et al. 2005); understanding in detail its properties might help to elucidate the precise role of GGT in the pathogenesis of atherosclerotic plaques, and the connection between organ damage, GGT levels and individual risk of disease.

In conclusion, cells of different origin (melanoma, prostate cancer and bronchial epithelium) share the ability to release a GGT form that corresponds to the b-GGT fraction found in serum of healthy individuals; despite its MW, b-GGT does not correspond to GGTladen VLDL. While supporting the hypothesis that liver is not the only source of serum GGT, the present findings point to the need of a better understanding of the nature and properties of the plasma GGT fractions, for a better clinical utilization of GGT as a biomarker of disease, and a better understanding of the pathogenesis of diseases associated with its increase in serum.

\section{Acknowledgments}

Decleration of interest: The authors report no conflicts of interest. The authors alone are responsible for the content and writing of the paper.

\section{References}

Corti A, Franzini M, Casini AF, Paolicchi A, Pompella A. (2008). Vitamin C supply to bronchial epithelial cells linked to glutathione availability in ELF - a role for secreted gamma-glutamyltransferase? J Cyst Fibros 7: 174-8.

Emdin M, Passino C, Michelassi C, Titta F, L'Abbate A, Donato L, Pompella A, Paolicchi A. (2001). Prognostic value of serum gamma-glutamyl transferase activity after myocardial infarction. Eur Heart J 22: 1802-7.

Emdin M, Pompella A, Paolicchi A. (2005). Gammaglutamyltransferase, atherosclerosis, and cardiovascular disease: triggering oxidative stress within the plaque. Circulation 112: 2078-80.

Franzini M, Corti A, Lorenzini E, Paolicchi A, Pompella A, De Cesare M, Perego P, Gatti L, Leone R, Apostoli P, Zunino F. (2006). Modulation of cell growth and cisplatin sensitivity by membrane gamma-glutamyltransferase in melanoma cells. Eur J Cancer 42: 2623-30.

Franzini M, Bramanti E, Ottaviano V, Ghiri E, Scatena F, Barsacchi R, Pompella A, Donato L, Emdin M, Paolicchi A. (2008). A high performance gel filtration chromatography method for gammaglutamyltransferase fraction analysis. Anal Biochem 374: 1-6.

Franzini M, Corti A, Martinelli B, Del Corso A, Emdin M, Parenti GF, Glauber M, Pompella A, Paolicchi A. (2009). Gamma- glutamyltransferase activity in human atherosclerotic plaquesbiochemical similarities with the circulating enzyme. Atherosclerosis 202: 119-27.

Huseby NE, Strömme JH. (1974). Practical points regarding routine determination of gamma-glutamyl transferase (gamma-GT) in serum with a kinetic method at 37 degrees C. Scand J Clin Lab Invest 34: 357-63.

Huseby NE. (1982). Multiple forms of serum gamma-glutamyltransferase. Association of the enzyme with lipoproteins. Clin Chim Acta 124: 103-12.

Kazemi-Shirazi L, Endler G, Winkler S, Schickbauer T, Wagner O, Marsik C. (2007). Gamma-glutamyltransferase and long-term survival: is it just the liver? Clin Chem 53: 940-6.

Lee DH, Jacobs DR Jr, Gross M, Kiefe CI, Roseman J, Lewis CE, Steffes M. (2003). Gamma-glutamyltransferase is a predictor of incident diabetes and hypertension: the Coronary Artery Risk Development in Young Adults (CARDIA) Study. Clin Chem 49: 1358-66.

Lee DH, Silventoinen K, Jacobs DR Jr, Jousilahti P, Tuomileto J. (2004). gamma-Glutamyltransferase, obesity, and the risk of type 2 diabetes: observational cohort study among 20,158 middle-aged men and women. J Clin Endocrinol Metab 89: 5410-4.

Lee DS, Evans JC, Robins SJ, Wilson PW, Albano I, Fox CS, Wang TJ, Benjamin EJ, D'Agostino RB, Vasan RS. (2007). Gamma glutamyl transferase and metabolic syndrome, cardiovascular disease, and mortality risk: the Framingham Heart Study. Arterioscler Thromb Vasc Biol 27: 127-33.

Meisinger C, Doring A, Schneider A, Lowel H, KORA Study Group. (2006). Serum gamma-glutamyltransferase is a predictor of incident coronary events in apparently healthy men from the general population. Atherosclerosis 189: 297-302.

Mortensen B, Huseby NE. (1997). Clearance of circulating gammaglutamyltransferase by the asialoglycoprotein receptor. Enzyme forms with different sialic acid content are eliminated at different clearance rates and without apparent desialylation. Clin Chim Acta 258: 47-58.

Nemesanszky E, Lott JA. (1985). Gamma-glutamyltransferase and its isoenzymes: progress and problems. Clin Chem 31: 797-803.

Paolicchi A, Emdin M, Ghliozeni E, Ciancia E, Passino C, Popoff G, Pompella A. (2004). Human atherosclerotic plaques contain gamma-glutamyl transpeptidase enzyme activity. Circulation 109: 1440.

Ruttmann E, Brant LJ, Concin H, Diem G, Rapp K, Ulmer H. (2005). gamma-Glutamyltransferase as a risk factor for cardiovascular disease mortality. An investigation in a cohort of 163,944 Austrian adults. Circulation 112: 2130-7.

Ryu S, Chang Y, Kim DI, Kim WS, Suh BS. (2007). Gammaglutamyltransferase as a predictor of chronic kidney disease in nonhypertensive and nondiabetic Korean men. Clin Chem 53: 71-7.

Sacchetti L, Castaldo G, Salvatore F. (1988). The gammaglutamyltransferase isoenzyme pattern in serum as a signal discriminating between hepatobiliary diseases, including neoplasias. Clin Chem 34: 352-5.

Visvikis A, Thioudellet C, Oster T, Fournel-Gigleux S, Wellman M, Siest G. (1991). High-level expression of enzymatically active mature human gamma-glutamyltransferase in transgenic V79 Chinese hamster cells. Proc Natl Acad Sci USA 88: 7361-5.

Wannamethee G, Ebrahim S, Shaper AG. (1995). Gammaglutamyltransferase: determinants and association with mortality from ischaemic heart disease and all causes. Am J Epidemiol 142: 699-708.

Wenham PR, Horn DB, Smith AF. (1984). Physical properties of $\gamma$-glutamyltransferase in human serum. Clin Chim Acta 141: 205-18.

Whitfield JB. (2001). Gamma glutamyl transferase. Crit Rev Clin Lab Sci 38: 263-355. 